Logos. Anales del Seminario de Metafísica

ISSN: 1575-6866

http://dx.doi.org/10.5209/ASEM.56840

\title{
Nietzsche al futuro
}

Mariano Rodríguez González ${ }^{1}$

Vogel, Beatrix (Hg.), Umwertung der Menschenwürde-Kontroversen mit und nach Nietzsche. Mit einem Vorwort von Michael von Brück. Freiburg / München, Karl Alber, $2014\left(2^{\mathrm{a}}\right), 426$ págs.

Antes de dar comienzo el libro propiamente dicho se nos condensa en apenas un párrafo el conjunto de circunstancias que dieron pie a su aparición. En primer lugar, el artículo primero de la Ley Fundamental de la República Federal de Alemania parte de la base de que la dignidad del hombre es inviolable. En segundo lugar, el joven filósofo Stefan Lorenz Sorgner, particularmente en su libro de 2010 Menschenwürde nach Nietzsche. Die Geschichte eines Begriffs, habría traído al foco de nuestra atención, señalando a la crítica nietzscheana del mismo y en el marco del actual debate del posthumanismo, el hecho de que el tradicional concepto de dignidad humana ya no tiene una justificación filosófica evidente, en el sentido de ir más allá de lo meramente convencional, pero tampoco una que le venga dada por un consenso social ni unánime ni suficiente. Por ello se hace hoy urgente replantear el sentido de la dignidad humana desde nuevas posibilidades de fundamentación. Lo que habría motivado, en tercer lugar, la organización de un encuentro interdisciplinar del Foro Nietzsche de Múnich en Octubre de 2012, para tratar y discutir tan compleja cuestión desde los puntos de vista del derecho constitucional, la filosofía y las denominadas ciencias de las religiones. Este grueso y denso volumen recogería entonces las intervenciones del encuentro.

Estamos ante un asunto importante, por lo tanto, una cuestión rotundamente actual. Dos de los méritos más notables de la obra serían, sin duda, encararla con valentía y honestidad, así como hacerle justicia en toda su complejidad. Se echa de ver enseguida la preocupación de la editora por asegurar la apariencia de unidad de las muy variadas contribuciones. En efecto, habría redactado Beatrix Vogel para el libro que comentamos, en su calidad de presidenta del Foro Nietzsche de Múnich, más de cien páginas de introducción y cerca de cuarenta de epílogo. Y mientras que en el epílogo sin duda consigue inspirarle las líneas que sería necesario trabajar en el futuro para intentar cerrar el debate de alguna manera, en la introducción el lector no llega a comprender del todo la razón por la que la editora le va narrando con parsimonia y detalle, uno por uno, los trabajos que comenzarán cuando ella por fin termine de desgranarlos. A no ser que repare en que, en efecto, la unidad del volumen no dejará de tornarse en algún momento problemática, incluso a pesar de los buenos

Universidad Complutense de Madrid 
deseos de Vogel y todo su concienzudo trabajo. De todos modos, al finalizar la obra se conseguirá caer en la cuenta de su bien planificada estructura dilemática.

La mejor manera de evitar esta dispersión de la primera vista no es tomar como punto de referencia el pensamiento nietzscheano, puesto que no pocos de los que intervienen en el volumen prescinden de él, y si otros lo incluyen en sus intervenciones lo harían desde muy contrapuestos puntos de vista y en ocasiones se ve a las claras que lo usan solo como pretexto. Sino situarse para partir de ella en la contribución del propio Sorgner, cuyas apreciaciones de la cuestión de la justificación actual del tradicional concepto de la dignidad humana, al fin y al cabo, fueron las que dieron origen, y por tanto sentido, a todo este debate que se lleva aquí a la imprenta. En síntesis, que en nuestros días las fronteras entre lo humano y lo animal, por un lado, y entre lo humano y lo computacional, por otro, se han tornado alarmantemente borrosas, y entonces el respeto a la dignidad del ser humano, punto ético nodal del humanismo de todos los pelajes, antiguo, cristiano y moderno, requiere de una justificación diferente a la que le habría venido otorgando tanto en su variedad platónico-cristiana como kantiana. Siempre en el caso, claro está, de que sigamos pensando que merece la pena luchar por la dignidad del humano, signifique lo que signifique. O que tantas y tantas cosas que ocurren hoy en nuestro mundo no convertirían a esa idealizada dignidad en papel mojado. El conflicto verdaderamente sangrante se localiza sin duda en el hecho de que la mera consideración de la dignidad humana lleva consigo la atribución de un valor absoluto o metafísico a la misma, en modo alguno convencional o producto de una evolución histórico social, algo que se pretende reflejar en la distinción a que podemos estipular que apuntan los términos alemanes Würde y Dignität. No por casualidad, evidentemente, la tajante afirmación que sigue en el artículo primero de la Ley Fundamental a la declaración de que la dignidad humana es inviolable no es sino la de que «respetarla y protegerla es obligación de todo poder estatal». Pero, por supuesto, la operación nietzscheana en la historia de nuestra cultura tiene el sentido general de una radical desfundamentación de toda pretensión a un valor absoluto o desvinculado de toda contingencia histórica.

Cuidándose de los aspectos referentes al derecho constitucional, y naturalmente en su calidad de expertos en este ámbito, tanto Böckenförde como Hufen aciertan a situar la justificación histórica del artículo primero de la Ley Fundamental de su país en relación con los innumerables abusos criminales del Tercer Reich y sus brutales violaciones de la dignidad humana. Pero por otro lado, ambos insisten en que el comentario jurídico que hoy sería pertinente a esa Ley Fundamental no puede pasar por alto los espectaculares progresos que han tenido lugar en Biomedicina y Biotecnología.

No dudan en ningún momento, sin embargo, de que la noción misma de dignidad humana puede persistir sin problemas en una organización jurídico-política como las occidentales, que se quiere neutral en lo religioso y en lo ideológico, porque se trataría de una noción propiamente filosófica que se impone por sí misma por su evidencia, también cuando lo que se destaca, como en nuestros días, es el reconocimiento mutuo y el derecho a ser atendido. Una noción kantiana que subraya la prohibición de la instrumentalizar a un ser racional, autoconsciente y capaz de autodeterminación, en tanto unidad anímico-corporal-espiritual, prolongándose en el fondo la antropología tradicional del pensamiento cristiano. Lo que sí habría que defender con argumentos, por ejemplo como hace Böckenförde, es la inclusión del aún no nacido en la protección jurídica de la dignidad que supuestamente ya 
le correspondería como ser humano programado genéticamente para serlo. En este punto sí que caben enfrentamientos dialécticos, hasta el punto de que el otro experto, Hufen, lo va a negar taxativamente, apoyándose precisamente en la misma noción kantiana que en cualquier caso se va a dar por descontada. Lo que sí incluye éste autor en la cobertura de la dignidad humana, en cambio, porque pretende descender del principio general a los casos concretos de la dignidad de los individuos, es la eliminación o la reducción del sufrimiento, desde el punto de vista de la atención a las particularidades de cada paciente y de su dolor. Con lo que se tendría una orientación bastante clara en diversos casos controvertidos de la investigación y la práctica médicas, como la fertilización in vitro, o la investigación en células madre o con sujetos incapaces de decisión.

Así que comprobamos que en esta primera parte de filosofía del derecho no se entra para nada en la cuestión central del debate. Porque en ningún momento duda esta aproximación del valor fundamentador absoluto que para el principio básico de toda norma jurídica tendría la filosofía humanista occidental, ya sea de raíz cristiana o ilustrada. Este comienzo del libro sirve para fijar con claridad la situación que constituye el punto de partida al que amenazaría la subversión efectuada por la operación nietzscheana, o también la apertura del problemático horizonte posthumano, elementos ambos que pensadores como Sorgner quieren considerar avanzando de la mano.

Será en la segunda parte, para la que se anuncia el tratamiento de los "aspectos filosóficos" del debate y del volumen, donde encontraremos la problematización de esa filosofía humanista, y por tanto el surgimiento de la controversia más viva.

La contribución de Sorgner que haría de quicio de toda la discusión lleva por título "Más allá de una rígida concepción del antropocentrismo", y el sugerente subtítulo de "Sobre el estatus moral de humanos, monos y computadoras". Si en el ser humano habita la dignidad y, sobre todo, si esa dignidad debe ser tenida en cualquier caso por inviolable, no es sino porque con él estaríamos ante un ser racional y libre, pensado por nuestra cultura al fin y al cabo como imago dei. De modo que los animales, desde este absolutismo metafísico del humanismo cristiano-kantiano, es decir, los animales en tanto privados de alma, como materia no fructificada que son, tienen que ser tratados ni más ni menos que como cosas. Pero semejante dualismo radical se sienten en nuestros días muchos ciudadanos con todo el derecho a cuestionarlo, sobre todo a la vista de lo que nos tienen que decir las aportaciones de las ciencias naturales desde la revolución darwiniana. Como habría hecho asimismo en su libro de 2010, Sorgner reflexiona críticamente de nuevo en su artículo sobre esta importante cuestión, y lo hace en diálogo con Nietzsche, filósofo que no en vano se ocupó intensamente con las discusiones científicas de su época. Pero además lo hace apoyado en la creencia de que una posición filosófica que no goce de un apoyo notorio por parte de la mayoría de ciudadanos cultos contemporáneos, sino tal vez todo lo contrario, tiene buenas razones para ser seriamente cuestionada.

Considera Sorgner, también con el apoyo de la ambigüedad nietzscheana en este terreno, que el Nihilismo en que nos hallamos sumidos en la actualidad constituye una verdadera conquista o avance digno de ser defendido y reivindicado. Porque el Nihilismo nos brindará, a su juicio, la oportunidad de esbozar una nueva concepción de la dignidad humana y también del estatuto propio de la persona, que superaría esa insostenible concepción rígida del antropocentrismo a la que hace referencia el título de su intervención. 
Pero lo que tenemos que subrayar es que el autor no acepta del todo la conocida posición de Singer por considerarla demasiado radical. Es cierto que subrayar muy antiheideggerianamente el hecho, hoy por hoy a duras penas discutible, de la mera diferencia de grado entre lo animal y lo propiamente humano, entre natura y cultura, deberá tener implicaciones morales, como quiere Singer. Pero por otra parte no podemos pasar por alto que las atrocidades a las que hemos venido asistiendo horrorizados a lo largo del siglo XX, y ya en lo que llevamos del XXI, nos convencerían de la necesidad del respeto a la dignidad humana. En este sentido Sorgner no tiene ningún reparo en subrayar con todo el énfasis posible que sería este reconocimiento y no otra cosa el que ha hecho posible el desarrollo de las sociedades democrático-liberales en las que tenemos la enorme fortuna de poder desarrollar nuestras vidas. Los dos extremos deben ser por tanto conciliados.

Y el modo de hacerlo sería establecer una jerarquía de sujetos morales, entre los que, para empezar, hemos de contar a algunas especies animales. En el terreno de la ficción, leemos con curiosidad, no es la primera vez que se representan humanos y primates manteniendo relaciones amorosas e incluso abiertamente eróticas, como por ejemplo en la novela del danés Peter Hoeg La mujer y el mono, de 1996.

Pero la frontera entre lo humano y lo computacional se habría tornado también cada vez más borrosa. Como probaría la reciente proliferación de ciborgs, propiciados por las BCIs (Brain Computer Interfaces), se hace difícil hoy dudar de la proximidad entre pensamientos humanos y procesos mecánicos y digitales. El proyecto en el que trabajan multitud de investigadores tan bien financiados no es otro que el del diseño de cerebros artificiales, desde el gato hasta el perro y el hombre, y para lograr este ambicioso objetivo probablemente se tendrán que desarrollar las biocomputadoras, de eficiencia difícilmente concebible en la actualidad. Claro que tenemos que pensar que una cosa es que la inteligencia artificial iguale o supere a la humana y otra diferente, en principio mucho más problemática, construir máquinas conscientes. Solo esto último nos invitaría o nos forzaría a incluir a las computadoras en esa jerarquía de sujetos morales a la que hemos hecho referencia. Porque entonces nos encontraríamos con que también ellas, como antes los animales, son capaces de sufrimiento. No por casualidad, el autor al que nos estamos refiriendo se iba a destacar ya hace algunos años por su incorporación del pensamiento nietzscheano al debate hoy en curso sobre el trans- y el posthumanismo, intentando desarrollar en conexión con el pensamiento del filósofo alemán algunos de los temas principales de la obra de Nick Bostrom, entre otros.

La jerarquía moral sorgneriana comprendería como sujetos a seres humanos, nacidos y aún no nacidos, pero también a otros animales no humanos como los delfines y primates superiores, y pudiera ser que también a máquinas inteligentes, atendiendo a dos criterios fundamentales, la capacidad de sufrir y el supuesto hecho de la conciencia superior, o mejor, el tan problemático de la autoconciencia (un ratón puede sufrir, sin duda, pero no es autoconsciente, pensamos). Con arreglo a lo cual se irían disponiendo personas de primer nivel, de segundo, etc. En el bien entendido de que solamente los humanos pueden ser portadores de la propiedad de la dignidad, sencillamente porque este concepto supone un logro y una conquista históricos cuyo reconocimiento debemos mantener a cualquier precio en tanto fundamento de las sociedades democráticas. Mientras que la cuestión de la dignidad de la vida humana aún no nacida seguirá siendo, para Sorgner, una cuestión abierta o controvertida, habida cuenta sobre todo de la disparidad de opiniones que suscita entre la ciudadanía. 
Dejando aparte, para no extendernos demasiado, las interesantes aportaciones de von Schirnding y de Bloch, respectivamente, a la situación presente de la educación humanística y a la prolongación del pensamiento nietzscheano, en lo tocante al nuevo hombre y a la dignidad humana, en autores como Hesse y Dürrenmatt, merece la pena destacar a continuación las muy interesantes y encontradas reflexiones de Düsing y sobre todo de esa especialista en la investigación nietzscheana que es Annemarie Pieper. La primera nos recuerda para empezar la importante afirmación hegeliana en el $\S 482$ de su Enciclopedia, según la cual el reconocimiento de la dignidad humana y del valor infinito de la persona se lo debemos al Cristianismo: «Esta idea ha venido al mundo por el Cristianismo, según el que el individuo como tal tiene un valor infinito», escribe allí el filósofo, justamente en tanto destinatario del amor de Dios. Es decir, si en la noción de dignidad humana vamos a buscar un principio de validez absoluta más allá de toda reducción a lo jurídico en el sentido de lo histórico convencional, puesto que tiene que poder oficiar como fundamento inconcuso de toda norma, no tendríamos otra opción que situarnos en un plano propiamente religioso, como otro participante en el volumen había subrayado también pero esta vez en relación al budismo. Y en la opinión de Düsing, a la interesante y valiosa ambigüedad nietzscheana que no dejaba de denunciar la utilización maquinal del hombre, le sucedería en el Nietzsche último un naturalismo biologicista absolutamente rechazable y peligroso. Por eso no deberíamos olvidar nunca que, como señaló en frase célebre Thomas Mann, quien se toma a Nietzsche al pie de la letra está perdido. En realidad, lo que no podemos dejar de observar en esta interesante contribución, por mucho que se intente matizar y aun enmascarar, es la necesidad que se subraya de volver a la vieja fundamentación absoluta, platónica, de todo discurso verdaderamente filosófico acerca de la dignidad humana.

La dignidad de la persona habría que basarla en suma en su ir más allá de sí, por encima de sí, en el hecho de su "trascendencia". Lo que ocurre es que hay dos maneras muy diferentes de pensarla. El malentendido biologicista se confunde de cabo a rabo porque pasa por alto que la phýsis nietzscheana, aunque atienda también a la biología de su época, no sería exactamente la de las actuales ciencias positivas de la vida. Antes bien, es todo lo que está vivo lo que va por encima de sí, pero en la línea del sentido de la Tierra, una trascendencia localizada siempre, paradójicamente, en el plano de inmanencia. Justamente porque el ser humano es algo que tiene que ser superado tiene todo el sentido del mundo hablar de la dignidad humana en el caso de Nietzsche, una dignidad por supuesto transvalorada. Si bien esto plantea lógicamente el problema de cómo conjugar esta dignidad con el principio del continuo al que se refería Abel, dado que es la vida misma la que consiste en el empuje de ir por encima de sí, en esa inquietud constitutiva de la phýsis, en toda la línea del gusano al hombre. Podría ser que lo crucial radicase en que el ser humano, a diferencia del gusano, es el único capaz de hacerse cargo de esta empresa esencial de autosuperación para impulsarla definitivamente de otra manera. Lo que no debe desvincularse del hecho de que el hombre para Nietzsche es el animal enfermo, el único animal que es vencido por la pulsión de muerte, y esto significa que su dignidad debe ser puesta tal vez en el esfuerzo feroz de remontar esa mortalidad que lo envolvería. Como si el animal no humano no muriera en sentido estricto, o no muriera en vida, que es la auténtica muerte. Con el humano habría llegado la hora de la gran decisión, el instante de la sombra más corta. 
Tal sería la deconstrucción nietzscheana del concepto de dignidad sobre la que piensa Pieper con encomiable lucidez, deconstrucción que nos llevaría, destruyéndola, de la creencia en el ser humano en tanto poseedor de un alma inmortal ajena al tiempo de la naturaleza, y por esa razón infinitamente valioso, al sentido de la Tierra como historia del cuerpo o proyección incesante más allá de los propios límites que se verifica en la continuidad de todo lo vivo. La nietzscheana naturalización de lo humano, su famosa retraducción de lo humano al homo natura, sí que nos obligaría por tanto a pensar la dignidad de las personas de un modo absolutamente terrenal, y la polémica surge entonces a partir del convencimiento de que esto es en realidad imposible. Sería el prejuicio judeo-cristiano de la indignidad de lo animal, por otra parte esencia del ideal ascético en tantas culturas, lo que a mi juicio hace tan problemática para muchos, incluso tan "peligrosa", la deconstrucción o transvaloración nietzscheana de la dignidad humana.

Por todo ello, y sobre todo por el convencimiento no poco común de que el de la dignidad humana solo poder devenir valor absoluto en tanto basado en la fe religiosa, no deja de parecerle lógico al lector que la parte que cierra el volumen se halle dedicada a los aspectos que se podrían denominar filosófico-religiosos mucho mejor que científico-religiosos. En este ámbito, el trabajo de Willers sería muy característico de esa peculiar hemenéutica de la sospecha de índole cristiana, que se sitúa ya para empezar en el marco a priori y absolutamente incuestionado según el cual todo producto intelectual de nuestra cultura es, quiéralo o no, dese cuenta o no su productor, radicalmente cristiano, aunque, como en el caso del supuesto cristianismo anticristiano de Nietzsche, habría que decir que paradójicamente cristiano. Es como lo del asunto del alma, que por supuesto es ya de entrada naturaliter christiana, por mucho que esa hermenéutica del Nietzsche hipercristiano que lo desenmascara como tal, pasaría por alto que es muy cuestionable que el alma exista, Nietzsche de hecho lo iba a negar al final con toda rotundidad en uno de sus escritos contra Wagner. En fin, se trata de una lectura ya vieja, la de la cristianización de Nietzsche, que se remontaría por ejemplo a Max Scheler, y que en la cultura hispana cuenta con una muestra muy brillante en María Zambrano. El esquema de Willers para aplicarla al caso del desafío nietzscheano a la dignidad humana sería sin duda ingenioso: de modo análogo a como en la doctrina cristiana la encarnación, el hacerse humano de Dios, sería en realidad la condición de la Gottwerdung o divinización del hombre, que es de lo que en el fondo se trata en todas las religiones habidas y por haber, en el pensamiento nietzscheano la destrucción de los valores del último hombre, e incluso del hombre superior, es decir, el Nihilismo en todo su rigor, va a ser la condición de posibilidad de que lo humano sea superado. El Übermensch, o sea, la divinización del humano que todas las religiones buscan. Incluso cabe añadir, zambranianamente, que precisamente el Dios cristiano murió (en la cruz) para que la Gottwerdung del hombre fuera posible. Exactamente igual que ocurre en Nietzsche, según los filósofos cristianos que todo lo metabolizan. Por cierto, y como se puede notar en el texto de Willers, lo metabolizan todo excepto Foucault, ahí se tienen que detener. En cualquier caso, la razón de ser de la dignidad humana en su valor infinito radicaría en este anhelo de divinización que nos posee a todos, al parecer, en mayor o menor medida.

La excelente contribución de Mall, finalmente, se sitúa en cambio en las formas de la religiosidad oriental para poder plantear la cuestión de la dignidad humana de manera anti-antropocéntrica, esto es, en la línea de apreciar la dignidad de la vida 
en general, la dignidad de los seres vivos del planeta. En este tipo de experiencia o de actitud religiosa que sería la de Oriente, el humano se comprende a sí mismo en tanto incardinado en el cosmos, y en consecuencia encuentra la paz dejándose llevar por la «gran naturaleza». Como no puede ser de otro modo, resuenan entonces en el lector ecos de movimientos también occidentales del pensar, como el estoicismo o incluso el análisis wittgensteiniano de la creencia religiosa que rematará en la actitud de temor reverencial ante el hecho de que el mundo sea. Este naturalismo que asume como propio el autor sería el que denomina "natural" pero no el "naturalístico" de las estrategias filosóficas que se limitan a mimetizar el formato explicativo de las ciencias naturales. A diferencia de este último, el naturalismo de la Gran Naturaleza o la Gran Casa del Ser no es reductivo sino que respetaría la relativa autonomía del espíritu humano en la cultura o en la historia, simplemente limitándose a sugerir que esa historia humana nunca podrá sobrepasar el ciclo que siempre se reitera de la gran naturaleza, el surgir, transcurrir, sucumbir de todos los seres individuales, su constitutiva temporalidad. Toda una llamada a la modestia más filosófica, por tanto, erguida contra el delirio de grandeza de la razón tecnocrática radicalmente emparentada, a decir verdad entonces, con la mentalidad cristiana más históricamente efectiva. Por muy espirituales y racionales que seamos y lleguemos a ser, permaneceremos siempre siendo lo que somos, porque ocurre que lo somos de raíz: seres naturales.

Mall termina viendo en el hecho de que al final de la trayectoria nietzscheana el pensamiento del eterno retorno cobrara primacía sobre los muy antrópicos de la voluntad de poder y el Übermensch -el eterno retorno como único Dios de Nietzsche según Löwith-, precisamente el reconocimiento, por parte de la modestia filosófica que se va a imponer en el pensador alemán, de que la dignidad humana reside en el saberse incrustado en la Gran Naturaleza. Como nos recuerda el autor, el emperador budista Ashoka hizo construir en el siglo III antes de Cristo un muy simbólico hospital para animales.

Este espléndido libro, que acierta a pensar a Nietzsche vinculado con el tema capital de la dignidad humana, y a ambos en su relación con las cuestiones del transy post-humanismo, nos deja entonces con un nuevo reto, el de reconducir los debates centrales de la filosofía de la tecnología y de la bioética por la senda problemática más adecuada a la altura de nuestro tiempo. 